\title{
QTL hotspots in eggplant (Solanum melongena) detected with a high resolution map and CIM analysis
}

\author{
Amy Frary • Anne Frary • Marie-Christine Daunay • \\ Koen Huvenaars $\cdot$ Rolf Mank $\cdot$ Sami Doğanlar
}

Received: 30 October 2013/Accepted: 29 December 2013/Published online: 18 January 2014

(C) Springer Science+Business Media Dordrecht 2014

\begin{abstract}
Fifty-eight $\mathrm{F}_{2}$ individuals derived from an interspecific cross between cultivated eggplant, Solanum melongena, and its wild relative, S. linnaeanum, were phenotyped for 42 plant, leaf, flower, and fruit traits. Composite interval mapping analysis using genotypic data from 736 molecular markers revealed the positions of 71 statistically significant $(P \leq 0.05)$ quantitative trait loci (QTL) influencing 32 of the morphological traits. Although most QTL were location-specific, QTL governing three traits (leaf lobing, leaf prickles and prickle anthocyanin) were detected in both experimental locations. Analysis of three additional traits (stem prickles, fruit calyx prickles and fruit length) in both locations yielded
\end{abstract}

The localization of QTL for 32 morphological traits on the high-resolution map of the eggplant genome has allowed hotspots and putative orthologs with other solanaceous species to be identified.

Electronic supplementary material The online version of this article (doi:10.1007/s10681-013-1060-6) contains supplementary material, which is available to authorized users.

\section{A. Frary}

Department of Biological Sciences, Mount Holyoke

College, South Hadley, MA 01075, USA

A. Frary $\cdot$ S. Doğanlar $(\bowtie)$

Plant Molecular Genetics Laboratory, Department of

Molecular Biology and Genetics, Izmir Institute of

Technology, Gulbahce Campus, Urla, Izmir 35430,

Turkey

e-mail: samidoganlar@iyte.edu.tr
QTL in similar but non-overlapping map positions. The majority (69\%) of the QTL corresponded closely with those detected in previous analyses of this data set. However the increased resolution of the linkage map combined with advances in QTL mapping permitted more precise localization, such that the average interval length of these QTL was reduced by $93 \%$. Thirty-one percent of the QTL were novel, suggesting that simple linear regression with a low density linkage map (the method used in previous studies of this population) missed a substantial portion of significant QTL. Hotspots of QTL affecting plant hairiness, prickliness, and pigmentation were identified on chromosomes 3,6 , and 10 , respectively, and may reflect the pleiotropic activity of single structural or regulatory genes at these positions. Based on synteny between the eggplant, tomato, potato and pepper genomes, putative orthologs were identified for $35 \%$ of the QTL suggesting strong conservation of gene function within the Solanaceae. These results should make it

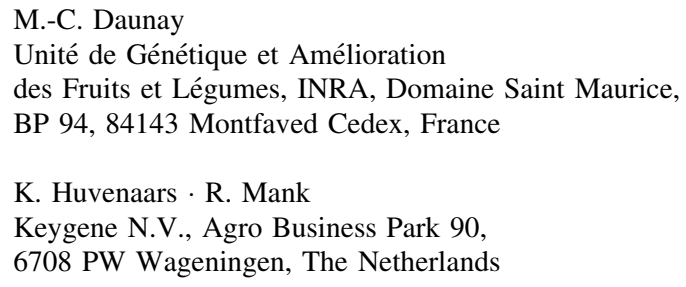


easier to target particular loci for map-based cloning and marker-assisted selection studies.

Keywords Solanum melongena - Quantitative trait loci $\cdot$ Gene conservation $\cdot$ Solanaceae

\section{Introduction}

The Solanaceae family of plants has long been of interest to plant geneticists both for its agricultural importance and its tractability as a model system. Members of the family are grown as vegetable crops (tomato, potato, pepper, eggplant, tomatillo, and pepino) and for ornamental purposes (Petunia, Calibrachoa, Datura, Brugmansia, Schizanthus, etc.). The cash crop tobacco also belongs to the family. Thus it is not surprising that some of the earliest work in gene and genome mapping as well as comparative genomics was done in the Solanaceae family. The construction of the first high-density molecular linkage map in tomato (Solanum lycopersicum) (Tanksley et al. 1992) was essential in establishing that species as a forerunner in the realm of quantitative trait locus (QTL) mapping and cloning (Alpert et al. 1995; Frary et al. 2000). The close relationship of tomato to potato $(S$. tuberosum), eggplant (S. melongena), and pepper (Capsicum spp.) has facilitated genome and trait mapping efforts in those species (Tanksley et al. 1992; Doganlar et al. 2002a; Livingstone et al. 1999).

Eggplant has lagged behind in the area of quantitative trait analysis in part because, in economic terms, it is a less important crop. Eggplant placed 25th in the FAO's top commodities ranking for 2010, well behind tomato (8th) and potato (13th) (FAO 2013). As a result, the first QTL mapping in eggplant was performed only 15 years ago and was limited to traits of breeder interest. The first such work involved the localization of a QTL for fruit shape on a random amplified polymorphism (RAPD) map for an intraspecific $S$. melongena $F_{2}$ population (derived from a cross between eggplant lines 'EPL1' and 'WCGR112-8') (Nunome et al. 1998). The addition of nearly 100 AFLP $^{\circledR}$ markers to the map allowed the detection of QTL for several other traits (fruit, stem, and calyx color) (Nunome et al. 2001). More recently, Barchi et al. (2012) developed a linkage map for their intraspecific $F_{2}$ population derived from a cross between two breeding lines, '305E40' and '67/3'. The map included over 400 restriction fragment length polymorphism
(RFLP) and single nucleotide polymorphism (SNP) markers and enabled the localization of QTL influencing seven pigmentation traits on eight of eggplant's twelve chromosomes. Thus a survey of the eggplant literature reveals that few quantitative traits have been analyzed in intraspecific populations. This fact highlights a serious hindrance to using such populations for QTL analysis: they display limited phenotypic variability. Although maps developed from intraspecific populations may be easier to exploit for the purposes of marker-assisted selection and breeding, the higher degree of morphological diversity in interspecific populations allows examination of a greater range of plant traits.

A S. linnaeanum MM195 $\times$ S. melongena MM738 $\mathrm{F}_{2}$ population was used by Doganlar et al. (2002a) to produce a molecular linkage map consisting of 233 RFLP markers at an average interval of $4.8 \mathrm{cM}$. Because S. linnaeanum is a prickly wild relative of eggplant that produces small, round, green, striped fruit while MM738 is a non-spiny commercial cultivar that produces large, oblong, purple fruit without striping, the $F_{2}$ population derived from these parents was highly polymorphic. Twenty-two domestication traits (fruit size, shape and color and plant prickliness) (Doganlar et al. 2002b) and 18 morphological traits (leaf, flower and fruit size, shape, appearance, and development) (Frary et al. 2003a) were evaluated in the population and subjected to single-point linear regression analysis. A total of 125 significant QTL were positioned on the interspecific map. Because of the relatively low resolution of the linkage map, the average length of the QTL detected in these companion studies was $35.8 \mathrm{cM}$, a fairly broad interval (considering the average linkage group length of $128 \mathrm{cM}$ ). In the current study, we have re-analyzed the domestication and morphological trait data for the $S$. linnaeanum $\times S$. melongena $\mathrm{F}_{2}$ population. Several advances in QTL mapping and eggplant genomics merited this strategy. Composite interval mapping (CIM) with marker cofactors is now the standard for QTL detection. By controlling for the effects of other markers on the trait, CIM is a more powerful method of QTL detection and provides greater accuracy in QTL localization (Zheng 1994). The development of a high-resolution map of the eggplant genome comprising over 850 AFLP, RFLP, and COSII (conserved ortholog set) markers at an average spacing of $1.8 \mathrm{cM}$ (Doganlar et al. in press) further enhances our ability to refine the positions of the QTL controlling the 
domestication and morphological traits. More precise locations of these loci are essential for marker-assisted selection and/or map-based cloning. In addition, they allow more detailed comparisons with QTL mapping studies in other solanaceous species. Such comparisons can help identify putative orthologs within the family, thereby shedding light on the evolutionary conservation and divergence of genomes.

\section{Materials and methods}

Plant population

The mapping population of $58 \mathrm{~F}_{2}$ individuals was generated from a cross between $S$. linnaeanum MM195 and S. melongena MM738 made by M.-C. Daunay at Institut National de la Recherche Agronomique, France. The female parent, S. linnaeanum Hepper \& Jaeger 'MM195', is a spiny wild relative that produces small, round, reticulate green fruit. The male parent, S. melongena L. 'MM738', is a non-spiny European commercial type that bears large, oblong, purple fruit. The $F_{2}$ plants were grown in the greenhouse in Ithaca, NY. Rooted vegetative cuttings were sent to Montfavet, France (FR), for field evaluations. Two plants of each genotype were planted at a single stake with 1 meter row spacing between genotypes. Replicates of the parental controls were also grown at both locations.

\section{Phenotype evaluations}

Greenhouse-grown $\mathrm{F}_{2}$ plants and controls were evaluated in Ithaca, New York (NY), during spring 1999. Field-grown plants were scored in Montfavet, FR, during July-October, 2000. A total of 42 plant, leaf, flower, and fruit traits were evaluated as described below (summarized in Online Resource 1).

Plant height (ht) in centimeters was determined in FR at the beginning of August. The number of days to first flowering (dtf) was counted in NY from the date of greenhouse transplanting until the opening of the first flower. The number of flowers per inflorescence (fln) was determined in FR at various times during the growing season and at several locations on the plant. The mean for each genotype was then used in the analysis. The mean number of fruit per infructescence (ftn) was determined in a similar way. Fruit set (fset) was an overall measure of fertility evaluated on a 0 (no fruit) to 5 (many fruit) scale.

Hairiness of vegetative plant parts was determined on a scale of 0 (no hairs) to 5 (very many hairs) in FR. The hairiness of plant apices (ah), leaves (lh), and stems (sh) was assessed by eye. The presence/absence of ovary hairs (ovh) was determined by microscopic examination of approximately three ovaries per genotype in the NY material. Fruit glossiness (fglo) was measured in FR on a scale of 1 (dull epidermis) to 3 (glossy epidermis).

Prickliness of leaves (lp), stems (sp) and fruit calyxes (ftcp) were assessed on a 1-5 scale in NY (1, no prickles; 5 , many prickles) and a $0-5$ scale ( 0 , no prickles; 5, many prickles) in FR. Flower calyx (flcp) and petiole ( $\mathrm{pp}$ ) prickliness were evaluated only in FR using the aforementioned scale.

Anthocyanin content of leaf laminae (lla), stems (sa), and prickles (pa) was scored on a 1 (green) to 3 (dark purple) scale in NY and a 0 (green) to 5 (dark purple) scale in FR. Leaf rib (lra) and flower corolla (ca) anthocyanin was assessed only in FR. Three separate fruit color traits were evaluated in both locations. Fruit anthocyanin presence (fap) recorded whether the fruits were green or purple. Fruit anthocyanin intensity (fai) scored the degree of pigmentation in the purple fruits only on a scale of 1 (light purple) to 3 (dark purple). Fruit stripe (fst) measured the secondary color repartition in the fruit as presence/ absence in NY and a 1-3 scale in FR (1, no stripes; 2, irregular striping; 3 , uniform reticulate striping). Two additional fruit color traits were scored in FR. Fruit chlorophyll netting (fcn) assessed the pattern of chlorophyll distribution in the fruit on a 1-3 scale in FR (1, no reticulation; 2, irregular reticulation; 3, uniform reticulation). Anthocyanin under the calyx (auc) was scored as a presence (1), absence (0) trait and served as an indirect measure of the sensitivity of fruit anthocyanin synthesis to light.

Size and shape parameters were evaluated for leaves, flowers, and fruit. Leaf width (lw) and length (11) of 12 leaves per genotype were measured (in $\mathrm{cm}$ ) in the early autumn in FR. The ratio between leaf length and width (1l/lw) was designated as leaf shape (lsh). Two traits described the appearance of leaves. Leaf lobing (llob) was scored on a scale of 1 (very weak lobing) to 5 (very strong lobing) in both FR and NY. Leaf surface appearance (lsur) was evaluated on a similar scale $(1=$ smooth leaf, $5=$ strongly wrinkled 
leaf) in FR. For the flower traits, approximately 12 inflorescences per genotype were harvested between July and October in FR; only the main flower of each inflorescence was measured. Flower diameter (fld) was measured in $\mathrm{mm}$, and flower shape (fls) was assessed on a 1 (orbicular) to 5 (star-shaped) scale. Ovary length (ovl), diameter (ovd), shape (ovs) and area (oa) were evaluated in NY by measuring (in $\mathrm{mm}$ ) transverse sections of ovaries harvested at anthesis. Ovary locule number (oln) was determined using transverse sections. In general, three ovaries were measured from each genotype for these trait analyses. Five representative fruits in NY and FR were harvested just prior to physiological ripeness for the analysis of fruit traits. Fruit weight (fw) was measured in grams. Fruit length (fl) and diameter (fd) were measured in $\mathrm{cm}$. Fruit shape (fs) was the ratio of length to diameter (fl/fd) such that round fruit had a shape index of 1 , oblate fruit had an index $<1$, and oblong fruit had an index $>1$. Fruit calyx size (cs) in FR was scaled according to the proportion of the fruit covered by the calyx ( $1=$ very short calyx, $<10 \%$ of the fruit length covered; $5=$ very long calyx, $>75 \%$ of fruit length covered).

QGene (Nelson 1997) was used to calculate correlation coefficients between traits.

\section{Genotype evaluations}

Molecular marker analysis and construction of the high-density eggplant map are described in Doganlar et al. (in press). A total of 736 AFLP, RFLP and COSII (conserved ortholog set) markers were used for QTL analysis. QGene version 4.0 (Joehanes and Nelson 2008) was used to map QTL. CIM (a method that combines interval mapping with multiple regression analysis) with automatic forward cofactor selection and a scan interval of $0.1 \mathrm{cM}$ was used for QTL detection. A genome-wide critical threshold value for an experiment-wise type I error rate, $\alpha=0.05$ and $\alpha=0.01$, was set by 1,000 random permutations of the trait data (Churchill and Doerge 1994). The percentages of phenotypic variance explained (PVE) were obtained from the generalized $R^{2}$ values (Nagelkerke 1991) calculated by QGene. Trait means, and gene actions $(d / a)$ were determined for each significant QTL using the CIM results. QTL detected in the present study were compared to those identified in the previous two studies conducted in this population
(Doganlar et al. 2002b; Frary et al. 2003a). Because these QTL were localized on a lower resolution version of the interspecific eggplant map (Doganlar et al. 2002a), the map positions and relative lengths of these previously identified QTL on the current molecular map (Doganlar et al. in press) were determined using shared RFLP markers as anchors.

Quantitative trait loci with $95 \%$ confidence intervals were drawn on the molecular linkage map of eggplant using MapChart 2.2 (Voorrips 2002). To identify QTL hotspots (clusters), a $20 \mathrm{cM}$ sliding window was advanced in $5 \mathrm{cM}$ increments across the linkage map. The number of QTL co-localizing within the window at each position in the genome was recorded with regions containing more than three QTL qualifying as hotspots.

\section{Results}

Phenotypic variation

A total of 42 plant, leaf, flower, and fruit traits were analyzed. The trait means are summarized in Online Resource 2. Fourteen of the traits were evaluated in both locations, 21 in FR only, and seven in NY only (Online Resource 1). The phenotypic distributions of the fourteen traits were compared across the two locations (data not shown). The majority of the traits showed a similar pattern, however some of the anthocyanin traits (sa, lla, fai, fst) tended to skew toward higher values in FR. This is not surprising as anthocyanin synthesis is closely tied to environmental conditions such as light intensity and temperature both of which are expected to be quite different for fieldgrown plants in FR as compared to greenhouse-grown plants in NY.

\section{Correlations between traits}

Significant $(P \leq 0.05)$ positive correlations existed between all of the traits measured in both FR and NY. These traits included fruit size and shape parameters (fruit weight, fruit shape, fruit diameter, fruit length), plant pigmentation (stem, prickle, leaf lamina anthocyanin, fruit anthocyanin presence and intensity, and fruit stripe) and prickle (stem, leaf, fruit calyx) traits as well as leaf lobing. Correlation coefficients ranged from 0.43 for fruit anthocyanin 
intensity (fai) to 0.96 for fruit shape (fs), with an average value of 0.79 .

A number of significant correlations were observed between traits measured at a single location. Those relationships are described in the following paragraphs and are summarized in Online Resource 2.

All of the prickle traits (sp, lp, pp, flcp, ftcp) were strongly associated with each other $(r=$ 0.70-0.92). Relationships between these prickle traits and several other morphological measures were also detected. Plant organ prickliness was positively correlated with leaf lobing (llob) $(r=0.59-0.83)$ as well as the anthocyanin content of stems (sa) $(r=0.29-0.38)$ and leaf laminae (lla) $(r=0.35-0.42)$. Significant associations were seen between most of the prickliness traits and the hairiness of stems (sh) $(r=0.28-0.29)$ and between leaf prickles and ovary hairs (ovh) $(r=0.39)$ as well as the size of calyxes (cs) $(r=0.32-0.56)$. In addition, associations were found between both flower (flcp) and fruit (ftcp) calyx prickliness and corolla pigmentation (ca) $(r=0.47-0.54)$. A strong negative relationship existed between prickliness and fruit glossiness (fglo) $(-0.49 \leq r \leq-0.64)$. Stem prickles (sp) were also negatively correlated with aspects of fruit size, namely fruit diameter (fd) and length (fl) ( $r=-0.36$ to 0.38 ).

While the traits assessing the hairiness of vegetative organs (ah, lh, sh) were strongly correlated with each other $(r=0.71-0.85)$, no association with ovary hairiness (ovh) was found. Similarly, while ah, lh, and sh were negatively correlated with fruit glossiness $(-0.39 \leq r \leq-0.50)$, ovh was unrelated to fglo. Negative relationships between fglo and two shape parameters, llob $(r=-0.41)$ and fruit shape (fs) $(r=-0.28)$, were observed. While fruit diameter (fd), a key determinant of fruit shape (defined as fruit length/fruit diameter) was associated with fglo $(r=0.36)$, fruit length (fl) was not.

Fruit length (fl) and diameter (fd) were strongly correlated ( $r=0.84-0.87)$, however only fl was significantly associated with fruit shape $(r=0.44-0.48)$. Not surprisingly, a similar relationship was seen in ovaries; ovary length (ovl) and diameter (ovd) were highly correlated with each other $(r=0.85)$ and ovs was significantly related to ovl only $(r=0.34)$. Interestingly, a positive association between calyx size and fs was seen $(r=0.40)$ such that more oblong fruit tended to have larger calyxes.
Most parameters of leaf size were unrelated. And, while a strong negative association between $1 \mathrm{w}$ and leaf shape (lsh, defined as 11/lw) existed $(r=-0.70)$, 11 and lsh were not significantly correlated.

All of the traits assessing pigmentation levels in vegetative tissues [stems (sa), leaf ribs (lra), leaf laminae (lla), and prickles (pa)] and flower corollas (ca) were positively correlated ( $r=0.36-0.94)$. Fruit anthocyanin presence (fap) was correlated with the other pigment traits however fruit anthocyanin intensity (fai) was less reliably associated with the other color traits, showing no significant connection with sa, pa or ca. Most of the anthocyanin traits were positively correlated with plant height (ht) $(r=0.31-0.38)$ however, fruit stripe (fst) was negatively correlated with ht $(r=-0.32)$. Negative associations also existed between fst and other aspects of plant growth, namely flower number (fln) $(r=-0.31)$ and fruit set (fset) $(r=-0.38)$.

Fruit set (fset) was significantly correlated with fruit and flower traits, including fln $(r=0.28)$, ftn $(r=0.61) \mathrm{fl}(r=0.29)$ and fw $(r=0.29)$. The correlation coefficient between flower and fruit number was 0.46 .

\section{QTL analysis}

A genetic map consisting of 736 AFLP, RFLP, and COSII markers was used for CIM of QTL. Logarithm of odds (LOD) thresholds for QTL declaration were calculated by 1,000 permutations of the data for each trait. The mean experimental LOD thresholds were 4.92 and 5.91 at the 5 and $1 \%$ significance levels, respectively. Seventy-one statistically significant $(P \leq 0.05)$ QTL impacting 32 traits mapped to 11 of eggplant's 12 linkage groups (Table 1; Online Resource 3). Seventy-five percent of these QTL met or exceeded the LOD threshold at the $1 \%$ level of significance. The average number of QTL identified per trait was 2.2. Fruit length (fl) and apex hairs (ah) yielded the greatest number of QTL: five each. The average number of QTL on each linkage group was 5.9, with linkage group 6 having the most (13 QTL) and linkage group 8 having the fewest (0 QTL). The size of the QTL ranged from 0 to $19.3 \mathrm{cM}$, with a mean QTL length of $3.4 \mathrm{cM}$. The percentage of phenotypic variation explained (PVE) by the QTL varied from a low of $33 \%$ to a high of $100 \%$; the mean phenotypic trait variance was $55 \%$. 


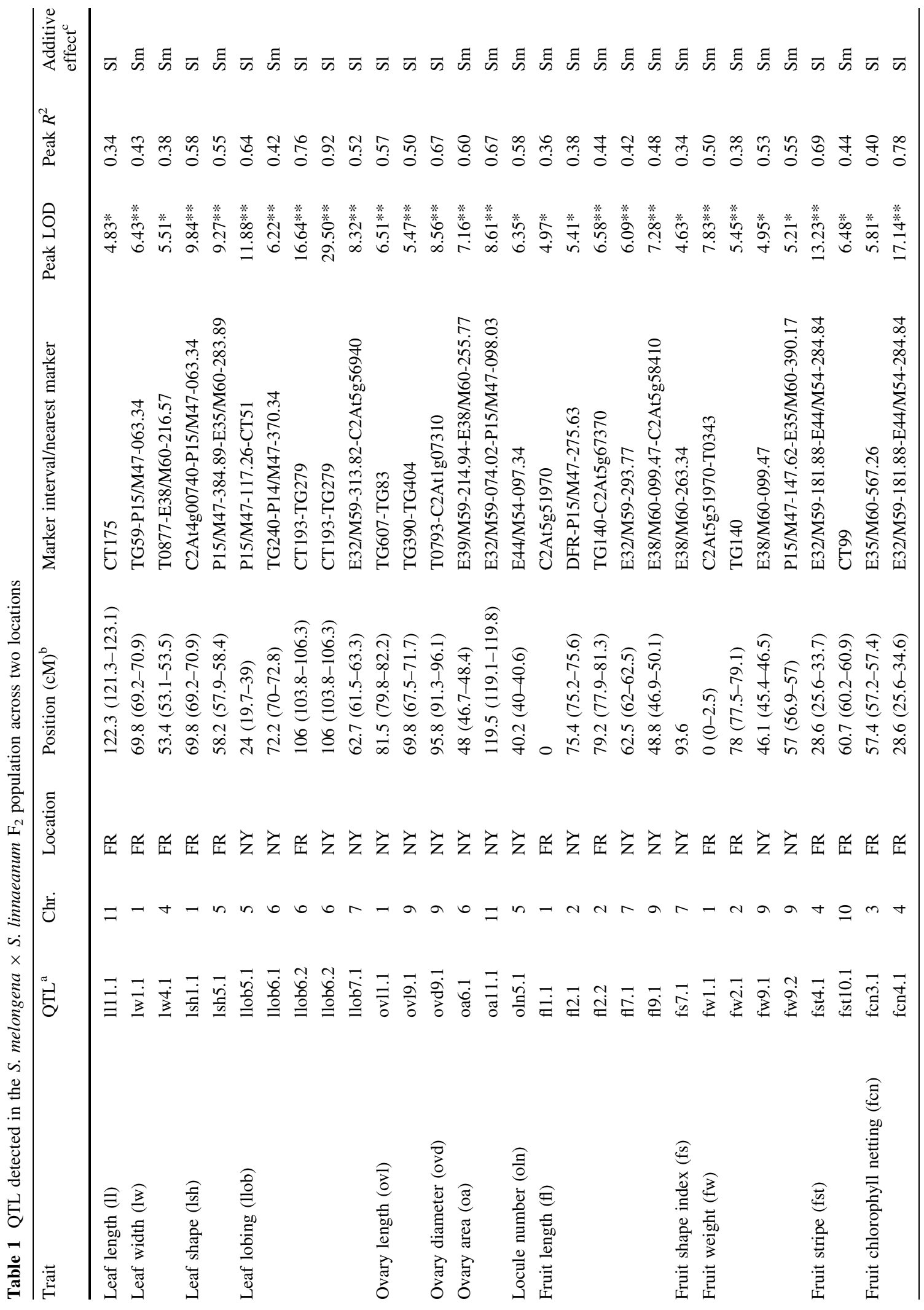




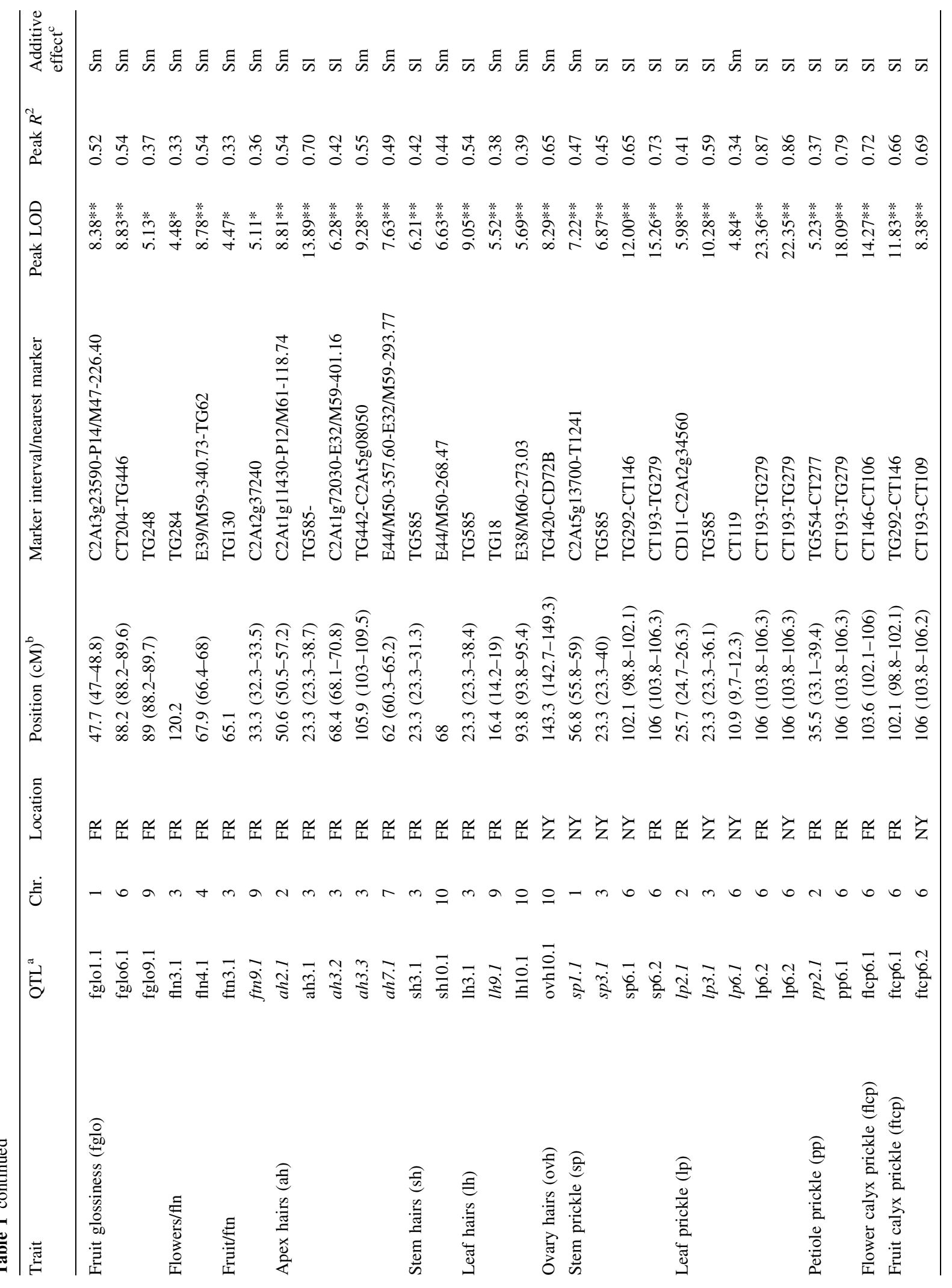




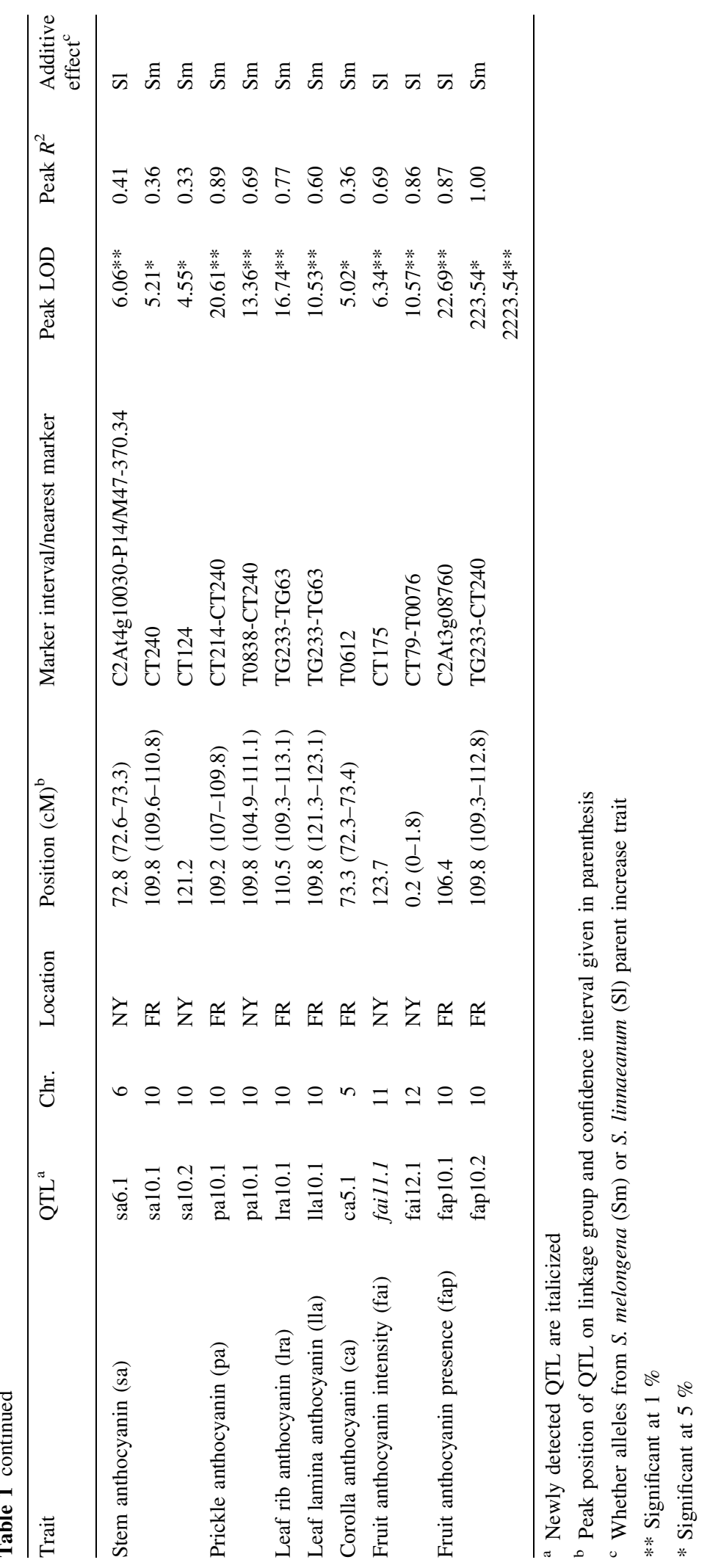


For the traits assessed in both locations, three QTL in corresponding positions were detected in NY and FR: llob6.2, lp6.2, and pa10.1. Analysis of three other traits in both locations yielded QTL in similar but nonoverlapping map positions: $f 2.1 / f l 2.2$, sp6.1/sp6.2, ftcp6.1/ftcp6.2. However, of the 23 QTL associated with traits measured in both NY and FR, the majority were specific to a single location.

Twenty-two of the QTL (31\%) identified in this study were novel, not reported in previous QTL analyses of this interspecific population. The map locations of the 49 remaining QTL corresponded fairly closely to those of QTL detected by Doganlar et al. (2002b) and Frary et al. (2003a) using simple linear regression analysis. The peak position of each of these QTL shifted an average of $\pm 6.8 \mathrm{cM}$ as compared to the map position of its previously identified counterpart. Average interval size changed dramatically with the new analysis: these common QTL averaged $2.8 \mathrm{cM}$ in length as compared to $39.2 \mathrm{cM}$ in the previous study.

Leaf size and shape traits

A single significant QTL explaining $34 \%$ of the phenotypic variation in leaf length was identified on chromosome 11 (ll11.1). Interestingly, S. linnaeanum alleles at this locus contributed toward increasing leaf length, an effect opposite to that expected.

Leaf width was influenced by QTL on chromosomes 1 and 4. $l w 1.1$ and $l w 4.1$ accounted for 43 and $38 \%$ of the phenotypic variation in leaf width, respectively. $S$. melongena alleles at both loci increased leaf width as expected. The QTL $l w 4.1$ was previously undetected in this population.

Quantitative trait loci on chromosomes 1 and 5 affected leaf shape, the ratio between leaf length and width. Individually, $l s h 1.1$ and $l s h 5.1$ explained 58 and $55 \%$, respectively, of the variation in leaf shape. Alleles at $l s h 1.1$ had effects opposite to those predicted based on the parental phenotypes.

Four QTL on chromosomes 5, 6 and 7 impacted the degree of leaf lobing. Of the two loci identified on chromosome six, llob6.1 was identified in NY and llob6.2 was identified in both growing environments (NY and FR). Interestingly, S. melongena alleles at llob6.1 had the unexpected effect of increasing lobing. The largest phenotypic effects on the trait were seen at llob6.2 (92\% PVE). llob5.1 and llob7.1 were previously undetected in the NY material. The more significant of these loci (llob5.1, $64 \%$ PVE) behaved in an additive manner.

No significant QTL were detected for leaf surface appearance (lsur).

Flower size and shape traits

Ovary length was affected by two QTL, ovll.1 and ovl9.1, which accounted for 57 and $50 \%$, respectively, of the phenotypic variation in the trait. S. linnaeanum alleles at both loci had the unexpected effect of increasing ovary length with ovll.1 alleles behaving in an additive manner. ovl9.1 was previously undetected in this population.

One QTL (ovd9.1) was associated with $67 \%$ of the variation in ovary diameter. As expected, S. linnaeanum alleles at this locus contributed toward wider ovaries.

Ovary area, as calculated from transverse sections, was controlled by two QTL, oa6.1 and oall.1 which explained $60-67 \%$ of the phenotypic variation in the trait. Parental alleles at both loci behaved in a predictable fashion with $S$. melongena alleles tending to augment ovary size.

Solanum melongena alleles at a single QTL increased ovary locule number. This QTL, oln5.1, accounted for $58 \%$ of the variation in the trait.

No significant QTL were detected for flower diameter (fld), flower shape (fls) or ovary shape (ovs).

Fruit size and shape traits

Five QTL impacting fruit length were identified, two in FR ( $f l 1.1$ and $f 2.2)$ and three in NY $(f l 2.1, f l 7.1$, and $f 9.1)$. $f l 1.1$ and $f 7.1$ were previously undetected in this population. Each locus accounted for between 36 and $48 \%$ of the variability in the length of the measured fruit. The two QTL on chromosome 2, fl2.1 and fl2.2, lay within $4 \mathrm{cM}$ of one another. Because the cultivated parent produces oblong fruit, it was not surprising that S. melongena alleles at all five loci were associated with longer fruit.

Fruit shape in the NY-grown plants was influenced by a QTL located on chromosome $7\left(f_{s} 7.1\right)$ which explained $34 \%$ of the variability in the trait. Parental alleles at this locus behaved in a predictable manner. No fruit shape QTL was detected in FR.

A total of four individual fruit weight QTL were identified, two ( $f w 1.1$ and $f w 2.1)$ in FR and two ( $f w 9.1$ 
and fw9.2) in NY. With the exception of fw2.1 (38\% PVE), each locus accounted for 50-55\% of the variability in fruit weight. As predicted, alleles from the cultivated parent increased fruit weight.

No significant QTL were identified for fruit diameter (fd) and calyx size (cs).

Fruit appearance traits

Fruit stripe in FR was controlled by QTL on chromosomes 4 and 10. S. linnaeanum alleles at $f_{s t 4.1}$ increased the degree of striping in fruit whereas $S$. melongena alleles had the effect of increasing fruit stripe at fst10.1. fst4.1 had a larger impact on phenotype, affecting $69 \%$ of the trait while $f_{s t 10.1}$ explained $44 \%$ of the variation in striping. No significant QTL influencing fruit stripe were detected in the NY-grown population. Fruit chlorophyll netting (fen) was also affected by two QTL. fcn4.1 overlapped with $f s t 4.1$ and accounted for $78 \%$ of the phenotypic variation in the trait. The locus on chromosome 3, fcn3.1, explained $40 \%$ of the variability in the trait. $S$. linneanum alleles increased fruit chlorophyll reticulation at both loci.

Quantitative trait loci associated with fruit glossiness were detected on three chromosomes. Each of the QTL on chromosomes 1 and 6, fglol.1 and fglo6.1 explained around $50 \%$ of the total variation in the trait. Alleles at fglo9.1 behaved in an additive manner and accounted for $39 \%$ of the variability in fruit glossiness. At all three loci, S. melongena alleles enhanced fruit glossiness.

\section{Plant traits}

Two QTL influenced the number of flowers per inflorescence, $f \ln 3.1$ and $f \ln 4.1$. $f \ln 4.1$ accounted for a greater amount of the phenotypic variation in the trait (54\%) than fln3.1 (33\%). S. melongena alleles at both loci increased flower number, an unexpected effect given the parental phenotypes.

Fruit number per infructescence was determined by QTL on chromosomes 3 and 9. These loci, ftn3.1 and ftn9.1 explained 33-36\% of the phenotypic variation in fruit number. Alleles from the cultivated parent increased fruit number at both loci.

Five QTL affecting apex hairs were detected. These included three loci on chromosome 3 , and one each on chromosomes 2 and 7. The most significant of the loci, ah3.1 explained $70 \%$ of phenotypic variation. The remaining loci (ah2.1, ah3.2, ah3.3, and ah7.1) were not previously identified in this population and accounted for $42-55 \%$ of the phenotypic variation in degree of hairiness at the apex. S. melongena alleles at $a h 2.1, a h 3.3$ and $a h 7.1$ led to hairier apices whereas $S$. linnaeanum alleles had that effect at ah3.1 and ah3.2.

Stem hairiness was controlled by loci on chromosomes 3 and 10. Each locus explained around $40 \%$ of the phenotypic variation in stem hairiness, however, $S$. linnaeanum alleles increased the trait at $s h 3.1$ but had the opposite effect at sh10.1.

Three QTL were associated with leaf hairiness, lh3.1, lh9.1, and lh10.1. The most significant of these loci was $l h 3.1$ (54\% PVE); the magnitude of effect at lh9.1 and $\operatorname{lh} 10.1$ was around $38 \%$. Interestingly, $S$. melongena alleles at the other two loci contributed toward hairier leaves. $l$ h9.1 was previously undetected in this population.

A single QTL for ovary hairiness was identified on chromosome 10. ovh10.1 explained $65 \%$ of the phenotypic variation in ovary hairiness. While $S$. linnaeanum ovaries are typically hairier than those of cultivated eggplant, wild species alleles at ovh10.1 decreased ovary hairiness.

The degree of prickliness of the stem was controlled by four QTL on three chromosomes. Three of these, sp1.1, sp3.1, sp6.1, were identified in the NY-grown plants. While the fourth QTL, sp6.2, was specific to FR, its peak LOD position was within $4 \mathrm{cM}$ of sp6.1. These two chromosome 6 loci all had a similar magnitude of effect (65-73\% PVE). spl.1 and sp3.1 were previously undetected in this population. Both explained around $46 \%$ of the phenotypic variation, however, $S$. melongena alleles at sp1.1 increased stem prickliness.

Four QTL influenced leaf prickliness. The most major of these, lp6.2 ( $\sim 86 \%$ PVE), was detected in both NY and FR. An additional locus was associated with leaf prickliness in FR: lp2.1 (41\% PVE) was not previously detected in this population. Two other novel loci, $l p 3.1$ and $l p 6.1$, were identified in the NY material and accounted for 59 and $34 \%$, respectively, of the phenotypic variability in leaf prickliness. $S$. linnaeanum alleles at all loci but one (lp6.1) acted to increase prickliness.

Petiole prickliness in FR was determined by QTL on chromosomes 2 and 6 . The locus on chromosome 6 , 
pp6.1 explained $79 \%$ of the variability in petiole prickliness. While $p p 2.1$ had a smaller effect on phenotype (37\% PVE), it represented a novel QTL for this trait. Petiole prickliness at both loci was enhanced by wild parent alleles. No QTL were significantly associated with petiole prickliness in NY.

A single flower calyx prickliness QTL, $f l c p 6.1$, was identified in the FR-grown population only. Seventytwo percent of the phenotypic variation in flower calyx prickliness was ascribed to this locus. Prickliness of the fruit calyx was also controlled by chromosome 6 loci. While ftcp6.1 was specific to FR and ftcp6.2 to $\mathrm{NY}$, the peak LOD positions of these two loci were within $4 \mathrm{cM}$ of each other and they had a similar magnitude of effect (66 and $69 \%$ PVE, respectively). S. linnaeanum alleles were responsible for increasing calyx prickliness at all of these loci.

No significant QTL were detected for plant height (ht), days to flowering (dtf), or fruit set (fset).

\section{Anthocyanin traits}

Three QTL on chromosomes 6 and 10 influenced stem anthocyanin levels. The effects of these loci on the phenotypic variation in stem pigmentation were similar, ranging from 33 to $41 \%$ PVE. However, sa6.1 and sal0.2 were specific to NY and sal0.1 was detected in FR only. S. linnaeanum alleles unexpectedly increased stem anthocyanin levels at sa6.1.

Prickle anthocyanin levels were determined by a single chromosome 10 QTL in both NY and FR however the phenotypic effects of pal0.1 were greater in FR (89 \% PVE) than NY (69\% PVE). Cultivated parent alleles at this locus enhanced prickle pigmentation.

Leaf rib and leaf lamina anthocyanin levels in FR were associated with the same region of chromosome 10. The QTL impacting leaf rib pigmentation (lra10.1) explained $80 \%$ of the phenotypic variation whereas that for leaf lamina pigmentation (lla10.1) explained only $40 \%$ of the variability in that trait. As expected, $S$. melongena alleles increased anthocyanin levels in leaf ribs and laminae.

A QTL on chromosome 5, ca5.1, influenced anthocyanin levels in the corolla and explained $36 \%$ of the variability in petal pigmentation. S. melongena alleles at the locus increased corolla anthocyanin levels.
Two QTL on chromosomes 11 and 12 controlled fruit anthocyanin intensity in NY. No QTL for this trait were detected in FR. fail2.1 explained $86 \%$ of the variability in fruit anthocyanin levels. fail1.1 accounted for $69 \%$ of the variability and was a novel QTL for this trait. Unexpectedly, wild parent alleles at both loci increased pigmentation in the fruit. The presence of anthocyanin in fruit was associated with two adjacent QTL on chromosome 10, fap10.1 and fap10.2. While both are major QTL, explaining 87 and $100 \%$, respectively, of the variability in the trait, these QTL were detected in FR but not NY. Cultivated and wild parent alleles had opposite effects at these two loci.

No significant QTL were detected for the anthocyanin under the calyx (auc) trait.

QTL hotspots

Quantitative trait loci hotspots, defined for the purposes of this study as clusters containing more than three adjacent or overlapping QTL within a $20 \mathrm{cM}$ window, were found on three linkage groups (Online Resource 3). These hotspots largely consisted of QTL for highly correlated traits. On the short arm of chromosome 3, a cluster of five QTL within a $16.7 \mathrm{cM}$ interval (between map positions 23.3 and $40 \mathrm{cM}$ ) impacted leaf (lh), stem (sh), and apex (ah) hairiness as well as leaf (lp) and stem (sp) prickliness. Strong positive correlations existed among the three hairiness traits $(r=0.71-0.85)$. Similarly, the two prickle traits had a correlation coefficient of 0.78. Correlations between the individual hair and prickle traits were weaker $(r=0.29$ for the association between stem hairs and leaf and stem prickles). A hotspot of seven QTL in a $18.2 \mathrm{cM}$ region on the long arm of chromosome 10 (between map positions 104.9 and $123.1 \mathrm{cM}$ ) consisted of loci linked to aspects of pigment production in stems (sa), prickles (pa), leaves (lla and lra), and fruit (fap). Once again, correlation analysis revealed all of these traits to be significantly related to one another. The largest QTL hotspot, eight loci within a $7.5 \mathrm{cM}$ region on the long arm of chromosome 6 (between map positions 98.8 and $106.3 \mathrm{cM})$, affected all five of the prickliness traits (leaf (lp), stem (sp), petiole (pp), flower calyx (flcp), and fruit calyx (ftcp) prickles) as well as leaf lobing (llob). As mentioned earlier, all of these traits were strongly associated ( $r=0.59-0.92)$. In addition to the hotspots, nine smaller clusters consisting of three QTL were 
identified on chromosomes 1 (two overlapping clusters within the 55-75 and 65-85 cM windows on the genetic map), 2 (65-85 cM window), 6 (70-90 cM window), 7 (60-80 cM window), 9 (three overlapping clusters: $30-50,40-60$ and 50-70 cM windows), and 11 (105-125 cM window). As with the hotspots, QTL controlling correlated traits occupied most of these clusters with the majority of the loci $(67 \%)$ influencing some aspect of organ size (ll, lw, lsh, ovl, fl, and fw).

\section{Discussion}

The discussion that follows is not meant to review the QTL exhaustively but rather to accomplish three goals. One goal is to examine QTL hotspots, defined as clusters containing more than three adjacent or overlapping QTL within a $20 \mathrm{cM}$ window. In some instances, we have given separate QTL designations to pairs of loci that affect a single trait and are in close proximity but do not overlap. Thus, $f l 2.1$ and $f l 2.2$ are separated by just $2.3 \mathrm{cM}$. Similarly, sp6.1/sp6.2 and ftcp6.1/ftcp6.2 are located within $1.7 \mathrm{cM}$ of their counterparts. In all three cases, one of the pair of QTL was detected in NY and the other in FR. For this reason we have named the QTL separately even though we suspect that more extensive phenotyping in a larger population or the use of a more accurate method of estimating the confidence interval would reveal them to be overlapping and therefore single loci. Colocalization of QTL for correlated traits was common and may suggest the pleiotropic activity of a single structural or regulatory gene. This phenomenon has been previously reported in tomato: fw2.2 and ovate are quantitative regulatory genes (Frary et al. 2000; Liu et al. 2002) that are most likely responsible for the clustering of fruit size and shape QTL on tomato chromosome 2. Alternatively, clusters of genes influencing related phenomena could arise from gene duplication followed by subfunctionalization such that the duplicate copies evolve slightly different but overlapping functions (for example, tissue-specific expression) (Lynch and Force 2000). Under such circumstances, natural selection would maintain the duplicate loci. Of course, in instances where the traits are obviously codependent (shape and size parameters), clustering of QTL is expected. As previously mentioned, this has been reported for fruit shape and weight QTL on tomato chromosome 2 (Eshed and
Zamir 1995; Grandillo et al. 1999; Lippman and Tanksley 2001). Similar QTL clusters are observed on tomato chromosome 4 (Monforte et al. 2001; Yates et al. 2004). Several strategies have been used to discriminate whether traits associated with clustered QTL are controlled by a single pleiotropic gene or two (or more) tightly-linked genes. Substitution mapping in near-isogenic lines revealed that fruit color and soluble solids content are controlled by two separate, linked QTL on chromosome 1 of the wild tomato relative $S$. chmielewskii (Frary et al. 2003b). Similarly, high-resolution linkage mapping of a $S$. pennellii chromosome 9 introgression uncovered two distinct but closely-linked loci influencing soluble solids content (Fridman et al. 2002). Association mapping is another approach and has also proven useful for resolving relationships between QTL and candidate genes (Wilson et al. 2004).

The second goal of this discussion is to identify potential orthologs. In a number of instances, the eggplant QTL detected in this study seem to have counterparts in the tomato and/or potato genome in the form of QTL or morphological markers for analogous traits (Table 2). Such cases indicate conserved gene function within the Solanaceae.

The third aim is to emphasize overlap with the results of other QTL studies in eggplant. Environmental factors contribute in myriad ways to trait phenotypes, therefore QTL detection and estimates of QTL effects (PVE) can be highly dependent upon experimental location. For the traits measured in both NY and FR, the majority of QTL were location-specific. Even for QTL identified in both locations, variable PVE values were obtained. These discrepancies are not surprising given that the two locations (greenhouse in NY, field in FR) represent quite different environments in terms of both biotic and abiotic factors (soil type and nutrients, light availability, temperature, relative humidity). These variable results limit the broad applicability of findings from QTL analyses. However, because of the profound influence that environmental conditions and genetic background can have on the phenotypic expression of quantitative traits, QTL detected in multiple locations and populations are more likely to represent major genes.

A hotspot for vegetative organ (apices, stems and leaves) hairiness QTL (ah3.1, sh3.1, lh3.1) was detected on chromosome 3 . These traits were wellcorrelated $(P<0.01), r=0.71-0.85$. Together these 
Table 2 QTL with putative conservation in the Solanaceae

\begin{tabular}{|c|c|c|c|c|c|}
\hline \multirow[t]{2}{*}{ Trait } & \multirow[t]{2}{*}{ QTL } & \multicolumn{2}{|l|}{ Putative ortholog } & \multirow[t]{2}{*}{ Locus type } & \multirow[t]{2}{*}{ Reference } \\
\hline & & Locus name & $\begin{array}{l}\text { Location } \\
\text { (eggplant/ }^{\text {other) }}{ }^{\mathrm{a}}\end{array}$ & & \\
\hline \multirow[t]{2}{*}{ Leaf length } & \multirow[t]{2}{*}{1111.1} & Leaf length QTL & $\mathrm{E} 1 / \mathrm{T} 4$ & QTL & Paran et al. (1997) \\
\hline & & lflr4.1 & $\mathrm{E} 1 / \mathrm{T} 4$ & QTL & Frary et al. (2004) \\
\hline \multirow[t]{4}{*}{ Leaf shape } & $\operatorname{lsh} 1.1$ & $\operatorname{lr} 1 b$ & $\mathrm{E} 1 / \mathrm{T} 1$ & QTL & $\begin{array}{l}\text { deVicente and } \\
\text { Tanksley (1993) }\end{array}$ \\
\hline & \multirow[t]{3}{*}{$1 \operatorname{sh} 5.1$} & $\operatorname{lr} 5$ & E5/T5 & QTL & $\begin{array}{l}\text { deVicente and } \\
\text { Tanksley (1993) }\end{array}$ \\
\hline & & lfw12.1 & E5/T12 & QTL & Frary et al. (2004) \\
\hline & & lfl12.1 & $\mathrm{E} 5 / \mathrm{T} 12$ & QTL & Frary et al. (2004) \\
\hline Leaf lobing & llob6.2 & Pts & E6/T6 & QTL & Tanksley et al. (1992) \\
\hline \multirow[t]{4}{*}{ Fruit length } & \multirow[t]{4}{*}{$\mathrm{fl} 2.1, \mathrm{fl} 2.2$} & ovate & $\mathrm{E} 2 / \mathrm{T} 2$ & Known gene & Ku et al. (1999) \\
\hline & & Frd2.1 & $\mathrm{E} 2 / \mathrm{Pe} 2$ & QTL & Barchi et al. (2009) \\
\hline & & Frs2.1 & $\mathrm{E} 2 / \mathrm{Pe} 2$ & QTL & Barchi et al. (2009) \\
\hline & & fs 2.1 & $\mathrm{E} 2 / \mathrm{Pe} 2$ & QTL & Zygier et al. (2005) \\
\hline Fruit shape index & fs7.1 & fs7.b & E7/T7 & QTL & Grandillo et al. (1999) \\
\hline \multirow[t]{5}{*}{ Fruit weight } & fw1.1 & fw1.1 & $\mathrm{E} 1 / \mathrm{T} 1$ & QTL & $\begin{array}{l}\text { Grandillo and } \\
\text { Tanksley (1996) }\end{array}$ \\
\hline & \multirow[t]{2}{*}{ fw2.1 } & fw2.2 & $\mathrm{E} 2 / \mathrm{T} 2$ & QTL & Frary et al. (2000) \\
\hline & & fw2.1 & $\mathrm{E} 2 / \mathrm{Pe} 2$ & QTL & $\begin{array}{l}\text { Ben Chaim et al. } \\
\text { (2001) }\end{array}$ \\
\hline & fw9.1 & fw9.1 & E9/T9 & QTL & Grandillo et al. (1999) \\
\hline & fw9.2 & fw9.2 & E9/T9 & QTL & Grandillo et al. (1999) \\
\hline \multirow{2}{*}{$\begin{array}{l}\text { Fruit stripe/chlorophyll } \\
\text { netting }\end{array}$} & \multirow[t]{2}{*}{ fst 4.1, fen 4.1} & Fs & $\mathrm{E} 4 / \mathrm{T} 10$ & Morphological & Tanksley et al. (1992) \\
\hline & & $\mathrm{u}$ & $\mathrm{E} 4 / \mathrm{T} 10$ & Known gene & Tanksley et al. (1992) \\
\hline Apex hairs & ah3.1 & $\mathrm{Ln}$ & E3/T3 & Morphological & Tanksley et al. (1992) \\
\hline \multirow[t]{2}{*}{ Stem and leaf hairs } & \multirow[t]{2}{*}{ sh10.1, lh10.1 } & TriIV-1 & E10/T5 & QTL & $\begin{array}{l}\text { Maliepaard et al. } \\
\text { (1995) }\end{array}$ \\
\hline & & $\begin{array}{l}\text { type B } \\
\text { trichome qtl }\end{array}$ & E10/Po5 & QTL & $\begin{array}{l}\text { Bonierbale et al. } \\
\text { (1994) }\end{array}$ \\
\hline Ovary hairs & ovh10.1 & $\mathrm{h}$ & E10/T10 & Morphological & Tanksley et al. (1992) \\
\hline \multirow{4}{*}{$\begin{array}{l}\text { Stem, leaf, prickle } \\
\text { anthocyanin }\end{array}$} & \multirow{4}{*}{$\begin{array}{l}\text { sa10.1, sa10.2, } \\
\text { 1la10.1, lra10.1, } \\
\text { pa10.1 }\end{array}$} & an $2 a$, an $2 b$ & $\mathrm{E} 10 / \mathrm{T} 10$ & Known gene & De Jong et al. (2004) \\
\hline & & ant1 & E10/T10 & Known gene & De Jong et al. (2004) \\
\hline & & chs & E10/T5 & Known gene & De Jong et al. (2004) \\
\hline & & $3 \mathrm{GT}$ & E10/T10 & Known gene & De Jong et al. (2004) \\
\hline Corolla anthocyanin & ca5.1 & $5 \mathrm{GT}$ & E5/T12 & Known gene & Barchi et al. (2012) \\
\hline \multirow{4}{*}{$\begin{array}{l}\text { Fruit anthocyanin } \\
\text { presence }\end{array}$} & \multirow[t]{4}{*}{ fap10.1, fap10.2 } & an2a, an $2 b$ & E10/T10 & Known gene & De Jong et al. (2004) \\
\hline & & ant1 & E10/T10 & Known gene & De Jong et al. (2004) \\
\hline & & chs & E10/T5 & Known gene & De Jong et al. (2004) \\
\hline & & $3 \mathrm{GT}$ & E10/T10 & Known gene & De Jong et al. (2004) \\
\hline
\end{tabular}

\footnotetext{
${ }^{a}$ Chromosome location in eggplant (E) and other solanaceous species [tomato (T), potato (Po) or pepper $(\mathrm{Pe})$ ]
}

results suggest that a single structural or regulatory gene may be influencing trichome density on vegetative organs. A putative ortholog, $L n$, which produces very hairy stems when mutated, maps in this vicinity in tomato (Tanksley et al. 1992). On chromosome 10, sh10.1 and lh10.1 mapped $25 \mathrm{cM}$ apart suggesting the 
existence of two hairiness genes in fairly close proximity on this chromosome. Trichome QTL in tomato (TriIV-1, type IV trichome production; Maliepaard et al. 1995) and potato (type B trichome density; Bonierbale et al. 1994) are possible orthologs of sh10.1 and lh10.1. Additional QTL influencing leaf and apex hairiness mapped in independent locations on chromosomes 2 (ah2.1), 3 (ah3.2, ah3.3), 7 (ah7.1), and $9(\mathrm{lh} 9.1)$ indicating that additional unrelated loci of slightly lesser effect are controlling these traits. Of these, $l h 9.1$ may be orthologous to TriIV-2, a QTL controlling type IV trichome density in tomato (Maliepaard et al. 1995). Ovary hairs were controlled by an independent locus on chromosome 10, ovh10.1, which is syntenic with the tomato $h$ (hairs absent) mutation (Tanksley et al. 1992).

The prickliness of leaves and stems showed a strong positive correlation $(r=0.71-0.88)$ and these prickle traits (lp3.1 and sp3.1) mapped together on chromosome 3 , indicating that a single gene may control the prickliness of both vegetative organs at this location. The previously mentioned QTL ah3.1, sh3.1, and lh3 are located in this same region of chromosome 3 . While sh was rather weakly correlated with $\mathrm{lp}$ and $\mathrm{sp}$ $(r=0.29)$, neither ah nor lh was significantly correlated with either prickle trait. This lack of strong correlation between prickliness and hairiness, combined with the fact that prickle and hair QTL did not overlap anywhere else in the genome, suggests that these two traits are under separate genetic control.

The hotspot of prickliness QTL (sp6.2, lp6.2, pp6.1, flcp6.1, ftcp6.1, ftcp6.2) on chromosome 6 is consistent with the high correlation coefficients among these traits ( $r=0.70-0.92)$ and suggests that a major structural or regulatory gene (accounting for 65-87\% of phenotypic variance) for prickliness resides in this location. That a locus controlling $>75 \%$ of the phenotypic variation in leaf lobing (llob6.2) maps in this same region is interesting. Deeply lobed leaves and prickly plant organs are highly correlated $(r=0.59-0.83)$ traits inherited from the wild $S$. linnaeanum parent. Close linkage between two (or more) genes for prickliness and leaf lobing would mean that deliberate selection against spines during eggplant domestication would have been accompanied by changes in leaf shape. Two tomato mutations map in the vicinity of llob6.2: Pts, Petroselinum and $c$, potato leaf (Liharska et al. 1997; Tanksley et al. 1992). Both mutations alter leaf complexity: Pts produces highly serrate, thrice-divided leaves while $c$ has the opposite effect, reducing both leaflet number and lobing (Hareven et al. 1996). Mapbased cloning of Pts showed it to encode a novel KNOX1 transcription factor lacking a homeodomain (Kimura et al. 2008). Two wild tomato species with thrice-compound leaves ( $S$. cheesmanii and S. galapagense) were found to overexpress Pts (Kimura et al. 2008). Thus a strong connection exists between this particular gene and the natural variation observed in wild Solanum species. Characterization of $C$ has shown it to be a member of a family of $R 2 R 3 M Y B$ transcription factors that control shoot branching. Because fully functional copies of $C$ have been found in S. melongena, the gene has been ruled out as the gene responsible for the differences in leaf dissection between cultivated and wild eggplant (Busch et al. 2011). These authors suggest that the phenotype of the $s f$ (solanifolia) mutant of tomato makes the $S f$ gene a more likely candidate for determining the degree of leaf indentation in eggplant. However, our study identified no QTL for leaf lobing on chromosome 3, the location of $S f$ (Tanksley et al. 1992).

Seven QTL for five highly correlated pigmentation traits (sa, pa, lla, lra, fap) map within a $16 \mathrm{cM}$ region of chromosome 10. In this same vicinity, Barchi et al. (2012) found a cluster of QTL controlling anthocyanin levels in six plant parts (stem, leaf lamina, leaf veins, corolla, calyx, peduncle) in their intraspecific $S$. melongena mapping population. Not surprisingly, several structural and regulatory genes involved in anthocyanin synthesis map to orthologous regions of the tomato genome. These include CHS (encoding chalcone synthase), 3GT (encoding 3-O-glucosyltransferase), and the transcription factors an $2 a$, $a n 2 b$, and ant (De Jong et al. 2004). Any of these genes are good candidates for those regulating pigment production in eggplant. In tomato, elevated fruit anthocyanins resulted when either the native gene or the ant 1 allele from the purple-fruited wild tomato $S$. chilense was overexpressed in S. lycopersicum (Mathews et al. 2003; Schreiber et al. 2012). As a master switch that upregulates nearby genes involved in anthocyanin biosynthesis (CHS) and modification (3GT) (Mathews et al. 2003), ANT1 could be an especially valuable target for improving eggplant peel color. While another major cluster of anthocyanin QTL was localized on chromosome 5 in the Barchi et al. (2012) intraspecific population, corolla anthocyanin (ca5.1) is the only trait that maps in this region 
in the current study. A single candidate gene resides in this region of the tomato genome, 5GT (encoding 5-Oglucosyltransferase) (Barchi et al. 2012). Of the other pigment QTL detected in the two studies, the only other overlap was seen on chromosome 11, between loci for abaxial leaf lamina anthocyanin (ablanE11.ML; Barchi et al. 2012) and fruit anthocyanin intensity (fail1.1).

Fruit stripe (fst) and fruit chlorophyll netting (fen) are related traits in that both measure pigmentation patterns in the fruit. Not surprisingly, a single region on chromosome 4 explains $69 \%$ (fst 4.1$)$ and $78 \%$ ( $c n 4.1)$ of the variance in each trait. These effects are likely due to the action of the eggplant $G v$ (green variegation) gene that controls chlorophyll reticulation (Daunay et al. 2004). However, interestingly, independent loci of lesser effect ( $f$ st 10.1 and $f c n 3.1$ ) were also identified for each character, suggesting that these traits may not be strictly monogenic. Both fst and fon were inherited independently of the other color traits, a result that agrees with Daunay et al.'s (2004) finding that chlorophyll distribution and anthocyanin presence in eggplant fruit are controlled separately. Potential tomato orthologs of $f s t 4.1$ and $f c n 4.1$ are $F s$ (fruit stripe) and $u$ (uniform ripening), two linked genes that affect striping (Clayberg 1962) and shoulder color (MacArthur 1934) in unripe fruit. $u$ has been recently characterized (Powell et al. 2012). It encodes a Golden 2-like transcription factor that regulates chlorophyll development during fruit formation. Thus, by selecting for unripe fruit that are a uniform light green (a product of the $u$ mutation), tomato breeders have selected for reduced chlorophyll content, a trait that has negatively impacted sugar levels in ripe fruit (Powell et al. 2012). If fst4.1 is indeed an ortholog of $u$, it would be a useful target for altering sugar content in eggplant breeding programs.

As expected, loci influencing codependent size and shape parameters of particular organs often localized to the same region of the genome; examples of this are: $l w 1.1$ and $l s h 1.1 ; f l 1.1$ and $f w 1.1 ; f l 2.1, f 2.2$ and $f w 2.1$; $f 9.1$ and $f w 9.1$. Based on syntenic map positions, several of the QTL affecting leaf size and shape appear to be conserved with loci in tomato. Thus, two potential orthologs of $l l 11.1$ are positioned on chromosome 4 of tomato: a leaf length QTL identified by Paran et al. (1997) and lfr4.l (leaflet width to length ratio) (Frary et al. 2004). The leaf shape QTL $l s h 1.1$ and $l s h 5.1$ also have counterparts in the tomato genome. Tomato $\operatorname{lrl} 1 b$ and $\operatorname{lr} 5$ (deVicente and Tanksley 1993), two QTL associated with leaflet width/ length ratio, map near eggplant $l s h 1.1$ and $l s h 5.1$, respectively. The leaflet width QTL (lfw12.1) on tomato chromosome 12 (Frary et al. 2004) is another possible ortholog of $l s h 5.1$. The fruit length loci on chromosome 2 ( $f l 2.1$ and $f l 2.2$ ) map in the same genomic region as tomato ovate (Ku et al. 1999) and several QTL in pepper. These include loci controlling pepper fruit diameter $(F r d 2.1)$ and shape (Frs2.1, $f_{s} 2.1$ ) (Barchi et al. 2009; Zygier et al. 2005). The sole fruit shape QTL identified in this study ( $\left.f_{s} 7.1\right)$ also has a counterpart in tomato, $f s 7 . b$ (Grandillo et al. 1999). Fruit weight is perhaps the most widely studied quantitative trait in tomato and possible orthologs exist for all four of the loci detected here. The map positions of $f w 1.1, f w 9.1$, and $f w 9.2$ are syntenic with synonymously named QTL in tomato (Grandillo and Tanksley 1996; Grandillo et al. 1999) while the location of eggplant $f w 2.1$ corresponds to that of tomato $f w 2.2$ (Frary et al. 2000), a gene that controls carpel cell number. Pepper fw2.1 also maps in this same region (Ben Chaim et al. 2001). These results suggest conservation of gene(s) affecting fruit size and shape on the long arm of chromosome 2 in eggplant, tomato, and pepper. One likely candidate is ovate which acts as a negative regulator of growth during early fruit development in tomato (Liu et al. 2002).

In a previous analysis of this interspecific eggplant population, simple linear regression analysis found 123 significant $(P \leq 0.01)$ QTL for the 40 morphological traits (Doganlar et al. 2002b; Frary et al. 2003a). Over half of those loci (54\%) were not detected in this follow-up study using CIM, with more stringent individual trait LOD thresholds $(P \leq 0.01)$ (determined empirically from 1,000 permutations of the data) to reduce the incidence of false positives. Whereas the QTL identified in the previous studies explained, on average, around $33 \%$ of the phenotypic variance in the traits, the average in this study is $55 \%$. Because each of the QTL identified in this study account for $>10 \%$ of PVE, all of the loci qualify as "major" genes, according to the definition suggested by Collard et al. (2005). However, it should be noted that the relatively small size of the mapping population (58 $\mathrm{F}_{2}$ individuals) has several consequences. In such populations, minor QTL are more difficult to detect and major QTL effects are generally overestimated (Vales et al. 2005). Thus the change in the 
magnitude of QTL effect may, in part, be explained by the elimination of false positives and minor QTLs. Another factor to consider is the differing densities of the maps used in the analyses (207 markers in the previous map, 736 in the current map). With improved genome coverage we are more likely to detect a greater number of linked markers associated with each trait; therefore the estimated of phenotypic effects should be more accurate than those obtained previously for this population.

In addition, improvements in the resolution of the eggplant linkage map have yielded QTL approximately $1 / 10^{\text {th }}$ the length of the corresponding loci in the previous studies. Thus, the current analysis has tended to identify fewer loci of greater effect that occupy more precise positions. Our re-examination of the trait data has yielded 22 novel QTL not found in the previous studies. The PVE of the newly identified QTL averaged $53 \%$, suggesting that CIM on the highdensity genetic map revealed loci that were completely missed by simple linear regression with the low density linkage map. Counterparts in the tomato genome have been proposed for over one-third (35\%) of the 71 QTL reported here (Table 2). Conserved gene function in $50 \%$ of the traits (for which significant QTL were identified) is thus expected to exist between tomato and eggplant.

In conclusion, the re-analysis of the morphological and domestication trait data for the $S$. linnaeanum $\times S$. melongena $\mathrm{F}_{2}$ population yielded valuable results. Using the genotypic data from a much larger number of eggplant-specific markers allowed the detection of hitherto unrevealed associations with phenotypic traits. Estimates of QTL effects were improved and individual QTL could be placed with greater accuracy on the high-density map. An important next step would be to confirm the positions and phenotypic effects of these QTL in a much larger mapping population. With this information, particular loci could be targeted for map-based cloning and marker-assisted selection studies. In addition these results provide a starting point for identifying putative orthologs between eggplant and tomato based on synteny. Intraspecific populations of eggplant have also been useful for developing high-density linkage maps that explore the synteny between the tomato and eggplant genomes (Barchi et al. 2012; Fukuoka et al. 2012) and provide for the possibility of additional quantitative trait analyses. Such analyses, combined with the recently released tomato genome sequence (Tomato Genome Consortium 2012), should facilitate further examination of conserved gene function in the Solanaceae, an economically important family of plants.

Acknowledgments This work was supported by a Career Project (TUBITAK 104T224) from the Scientific and Technical Research Council of Turkey to Sami Doğanlar. This execution of the AFLP marker work was financially supported by DeRuiterZonen C.V., Rijk Zwaan Zaadteelt and Zaadhandel B.V., and Vilmorin Clause \& Cie S.A. The AFLP ${ }^{\circledR}$ technology is covered by patents and/or patent applications of Keygene N.V. AFLP and KeyGene are registered trademarks of Keygene N.V. Other trademarks are the property of their respective owners.

Conflict of interest The authors declare that they have no conflict of interest.

\section{References}

Alpert K, Grandillo S, Tanksley SD (1995) fw2.2: a major QTL controlling fruit weight is common to both red- and greenfruited tomato species. Theor Appl Genet 91:994-1000

Barchi L, Lefebvre V, Sage-Palloix A-M, Lanteri S, Palloix A (2009) QTL analysis of plant development and fruit traits in pepper and performance of selective phenotyping. Theor Appl Genet 118:1157-1171

Barchi L, Lanteri S, Portis E, Vale G, Volante A, Pulcini L, Ciriaci T, Acciarri N, Barbierato V, Toppino L, Rotino GL (2012) A RAD tag derived marker based eggplant linkage map and location of QTLs determining anthocyanin pigmentation. PLoS ONE 7:e43740

Ben Chaim A, Paran I, Grube RC, Jahn M, van Wijk R, Peleman J (2001) QTL mapping of fruit-related traits in pepper (Capsicum annuum). Theor Appl Genet 102:1016-1028

Bonierbale MW, Plaisted RL, Pineda O, Tanksley SD (1994) QTL analysis of trichome-mediated insect resistance in potato. Theor Appl Genet 87:973-987

Busch BL, Schmitz G, Rossmann S, Piron F, Ding J, Bendahmane A, Theres K (2011) Shoot branching and leaf dissection in tomato are regulated by homologous gene modules. Plant Cell 23:3595-3609

Churchill GA, Doerge RW (1994) Empirical threshold values for quantitative trait mapping. Genetics 138:963-971

Clayberg CD (1962) Inheritance and linkage of fruit stripe Fs. Rep Tomato Genet Coop 12:22-23

Collard B, Jahufer M, Brouwer J, Pang E (2005) An introduction to markers, quantitative trait loci (QTL) mapping and marker-assisted selection for crop improvement: the basic concepts. Euphytica 142:169-196

Daunay MC, Aubert S, Frary A, Doganlar S, Lester RN, Barendse G, van der Weerden G, Hennart JW, Haanstra J, Dauphin F, Jullian E (2004) Eggplant (Solanum melongena) fruit colour: pigments measurements and genetics. In: 
Proceedings of the XIIth EUCARPIA meeting on genetics and breeding of Capsicum and eggplant, 17-19 May 2004, Noordwijkerhout, The Netherlands, pp 108-116

De Jong WS, Eannetta NT, De Jong DM, Bodis M (2004) Candidate gene analysis of anthocyanin pigmentation loci in the Solanaceae. Theor Appl Genet 108:423-432

deVicente MC, Tanksley SD (1993) QTL analysis of transgressive segregation in an interspecific tomato cross. Genetics 134:585-596

Doganlar S, Frary A, Daunay M, Lester R, Tanksley S (2002a) A comparative genetic linkage map of eggplant (Solanum melongena) and its implications for genome evolution in the Solanaceae. Genetics 161:1697-1711

Doganlar S, Frary A, Daunay MC, Lester RN, Tanksley SD (2002b) Conservation of gene function in the Solanaceae as revealed by comparative mapping of domestication traits in eggplant. Genetics 161:1713-1726

Doganlar S, Frary A, Daunay MC, Huvenaars K, Mank R, Frary A (in press) High resolution map of eggplant (Solanum melongena) reveals extensive chromosome rearrangement in domesticated members of the Solanaceae. Euphytica

Eshed Y, Zamir D (1995) An introgression line population of Lycopersicon pennellii in the cultivated tomato enables the identification and fine-mapping of yield-associated QTL. Genetics 141:1147-1162

FAO Statistics (2013) http://faostat.fao.org. Accessed 15 Jan 2013

Frary A, Nesbitt TC, Frary A, Grandillo S, van der Knapp E, Cong B, Liu J, Meller J, Elber R, Alpert KB, Tanskley SD (2000) fw2.2: a quantitative trait locus key to the evolution of tomato fruit size. Science 289:85-88

Frary A, Doganlar S, Daunay MC, Tanksley SD (2003a) QTL analysis of morphological traits in eggplant and implications for conservation of gene function during evolution of Solanaceous species. Theor Appl Genet 107:359-370

Frary A, Doganlar S, Frampton A, Fulton T, Uhlig J, Yates H, Tanksley S (2003b) Fine mapping of quantitative trait loci for improved fruit characteristics from Lycopersicon chmielewskii chromosome 1. Genome 46:235-243

Frary A, Fritz LA, Tanksley SD (2004) A comparative study of the genetic bases of natural variation in tomato leaf sepal and petal morphology. Theor Appl Genet 109:523-533

Fridman E, Liu YS, Carmel-Goren L, Gur A, Shoresh M, Pleban T, Eshed Y, Zamir D (2002) Two tightly linked QTLs modify tomato sugar content via different physiological pathways. Mon Genet Genomics 266:821-826

Fukuoka H, Miyatake K, Nunome T, Negoro S, Shirasawa K, Isobe S, Asamizu E, Yamaguchi H, Ohyama A (2012) Development of gene-based markers and construction of an integrated linkage map in eggplant by using Solanum orthologous (SOL) gene sets. Theor Appl Genet 125:47-56

Grandillo S, Tanksley SD (1996) Analysis of horticultural traits differentiating the cultivated tomato from the closely related species Lycopersicon pimpinellifolium. Theor Appl Genet 92:935-951

Grandillo S, Ku HM, Tanksley SD (1999) Identifying the loci responsible for natural variation in fruit size and shape in tomato. Theor Appl Genet 99:978-987

Hareven D, Gutfinger T, Parnis A, Eshed Y, Lifschitz E (1996) The making of a compound tomato leaf: genetic manipulation of leaf architecture in tomato. Cell 84:735-744
Joehanes R, Nelson JC (2008) QGene 4.0 an extensible Java QTL-analysis platform. Bioinformatics 24:2788-2789

Kimura S, Koenig D, Kang J, Yoong FY, Sinha N (2008) Natural variation in leaf morphology results from mutation of a novel KNOX gene. Curr Biol 18:672-677

Ku H-M, Doganlar S, Chen K-Y, Tanksley SD (1999) The genetic basis of pear-shaped tomato fruit. Theor Appl Genet 9:844-850

Liharska TB, Hontelez J, van Kammen A, Zabel P, Koornneef M (1997) Molecular mapping around the centromere of tomato chromosome 6 using irradiation-induced deletions. Theor Appl Genet 95:969-974

Lippman Z, Tanksley SD (2001) Dissecting the genetic pathway to extreme fruit size in tomato using a cross between the small-fruited wild species Lycopersicon pimpinellifolium and L. esculentum var. Giant Heirloom. Genetics 158:413422

Liu J, van Eck J, Cong B, Tanksley SD (2002) A new class of regulatory genes underlying the cause of pear-shaped tomato fruit. Proc Natl Acad Sci USA 99:13302-13306

Livingstone KD, Lackney VK, Blauth JR, van Wijk R, Jahn MK (1999) Genome mapping in Capsicum and the evolution of genome structure in the Solanaceae. Genetics 152:1183-1202

Lynch M, Force A (2000) The probability of duplicate gene preservation by subfunctionalization. Genetics 154:459-473

MacArthur JW (1934) Linkage groups in the tomato. J Genet 29:123-133

Maliepaard C, Bas N, van Heusden S, Kos J, Pet G, Verkerk R, Vrielink R, Zabel P, Lindhout P (1995) Mapping of QTLs for glandular trichome densities and Trialeurodes vaporariorum (greenhouse whitefly) resistance in an $\mathrm{F}_{2}$ from Lycopersicon esculentum $\times$ Lycopersicon hirsutum $\mathrm{f}$. glabratum. Heredity 75:425-433

Mathews H, Clendennen SK, Caldwell CG, Liu XL, Connors K, Matheis N, Schuster DK, Menasco DJ, Wagoner W, Lightnew J, Wagner DR (2003) Activation tagging in tomato identifies a transcriptional regulator of anthocyanin biosynthesis modification and transport. Plant Cell 15: $1689-1703$

Monforte A, Friedman E, Zamir D, Tanksley SD (2001) Comparison of a set of allelic QTL-NILs for chromosome 4 of tomato: deductions about natural variation and implications for germplasm collection. Theor Appl Genet 102:572590

Nagelkerke NJD (1991) A note on a general definition of the coefficient of determination. Biometrika 78:691-692

Nelson JC (1997) QGene: software for marker-based genomic analysis and breeding. Mol Breed 3:229-235

Nunome T, Yoshida T, Hirai M (1998) Genetic linkage map of eggplant. In: Proceedings of the 10th Eucarpia meeting on genetics and breeding of Capsicum and eggplant, Avignon France, pp 239-242

Nunome T, Ishiguro K, Yoshida T, Hirai M (2001) Mapping of fruit shape and color development traits in eggplant (Solanum melongena L.) based on RAPD and AFLP markers. Breed Sci 51:19-26

Paran I, Goldman I, Zamir D (1997) QTL analysis of morphological traits in a tomato recombinant inbred line population. Genome 40:242-248

Powell ALT, Nguyen CV, Hill T, Cheng KL, Figueroa-Balderas R, Aktas H, Ashrafi H, Pons C, Fernandez-Muñoz R, 
Vicente A, Lopez-Baltazar J, Barry CS, Liu Y, Chetelat R, Granell A, van Deynze A, Giovannoni JJ, Bennett AB (2012) Uniform ripening encodes a Golden 2-like transcription factor regulating tomato fruit chloroplast development. Science 336:1711-1715

Schreiber G, Reuveni M, Evenor D, Oren-Shamir M, Ovadia R, Sapir-Mir M, Bootbool-Man A, Nahon S, Shlomo H, Chen L, Levin I (2012) ANTHOCYANIN1 from Solanum chilense is more efficient in accumulating anthocyanin metabolites than its Solanum lycopersicum counterpart in association with the ANTHOCYANIN FRUIT phenotype of tomato. Theor Appl Genet 124:295-307

Tanksley SD, Ganal MW, de Prince JP, Vicente MC, Bonierbale MW, Broun P, Fulton TM, Giovannoni JJ, Grandillo S, Martin GB, Messeguer R, Miller JC, Miller L, Paterson AH, Pineda O, Roder S, Wing RA, Wu W, Young ND (1992) High-density linkage maps of the tomato and potato genomes. Genetics 132:1141-1160

Tomato Genome Consortium (2012) The tomato genome sequence provides insights into fleshy fruit evolution. Nature 485:635-641
Vales MI, Schon CC, Capettini F, Chen XM, Corey AE, Mather DE, Mundt CC, Richardson KL, Sandoval-Islas JS, Utz HF, Hayes PM (2005) Effect of population size on the estimation of QTL: a test using resistance to barley rust stripe. Theor Appl Genet 111:1260-1270

Voorrips RE (2002) MapChart: software for the graphical presentation of linkage maps and QTLs. J Hered 93:77-78

Wilson LM, Whitt SR, Ibanez AM, Rocheford TR, Goodman MM, Buckler ES (2004) Dissection of maize kernel composition and starch production by candidate gene association. Plant Cell 16:2719-2733

Yates HE, Frary A, Doganlar S, Frampton A, Eannetta N, Uhlig J, Tanksley SD (2004) Comparative fine mapping of fruit quality QTLs on chromosome 4 introgressions derived from two wild tomato species. Euphytica 135:283-296

Zheng ZB (1994) Precision mapping of quantitative trait loci. Genetics 136:1457-1468

Zygier S, Chaim A-B, Efrati A, Kaluzky G, Borovsky Y, Paran I (2005) QTLs mapping for fruit size and shape in chromosomes 2 and 4 in pepper and a comparison of the pepper QTL map with that of tomato. Theor Appl Genet 111:437-445 